Journal of Social Sciences 6 (2): 162-166, 2010

ISSN 1549-3652

(C) 2010 Science Publications

\title{
A Review: Dominance, Marital Satisfaction and Female Aggression
}

\author{
Ali Edalati and Ma'rof Redzuan \\ Department of Human Development and Family Studies, \\ Faculty of Human Ecology, University Putra Malaysia, Malaysia
}

\begin{abstract}
Problem statement: Several studies conducted on dominance, marital satisfaction and female aggression (physical and psychological) are the primary concern of the review done in this study. This article contains two parts; the first part touches on the findings which show female dominance has relationship with aggression. The second section is concerned on studies which have shown marital satisfaction has correlation with female aggression. According to the existing literature, the rate of female aggression has relationship with dominance and marital satisfaction. Nevertheless, in spite of this fact, less research has been carried out on dominance, marital satisfaction and female aggression to achieve better family life and a better society in general. Conclusion: Without the studies on women aggression, the conflict behavior in the family related to aggression will not be solved. Researchers must pay more attention towards female aggression.
\end{abstract}

Key words: Women aggression, female aggression, dominance, marital satisfaction

\section{INTRODUCTION}

In this research, the researcher has reviewed available literature on dominance and marital satisfaction that involved in the female aggression. These variables will be identified in as much as they are related to female aggressive behavior. A noticeable majority of the researches conducted so far have included variables such as power, dominance and marital satisfaction in family, domestic violence as well as female aggression. However, in comparison to male aggression, few studies have been carried out on female aggression. Their findings show that female aggression is not less than that of male aggression in many countries of the world (Straus, 2008). Archer (2000) argues that females are slightly more likely to use physical aggression against their husband than men. There is no evidence that women must be less hostile to get into aggression than males.

In a comprehensive, cross-cultural survey of thirty two nations, Straus (2008) has investigated patterns of violence with respect to the roles of male and female participants in demonstrating a violence-marked behavior. Along with other findings, it was found that almost a third of the females being surveyed as well as the males have physically assaulted their dating mates and/or partners within a certain period of twelve months. Marital satisfaction is lower in couples where aggressive acts have happened. According to Hotaling and Sugarman (1990), marital dissatisfaction is the most consistent risk marker in terms of male aggression and female victimization.

Dominance and relationship with female aggression: Power and its accessibility is one of the most important issues in the families. In more traditional societies, the power was an important phenomenon in the family and most often it belonged to men. The occurrence of patrilineal led to the enhancement of male dominance and brought men many benefits. In contemporary societies, gender roles in the family is not convincing any more. Due to social changes, male domination is changing within the family sphere and with women's involvement in the decision-making process, gender inequality in the family is going to be undermined.

Dominance has been discussed frequently because those dominant need to challenge to keep it. That is why analysts are today trying to recognize the authority in the families and who should hold the authority and make decisions. Dominance and the phenomenon of acquiring it is a historical event and are practically and mentally considered. In the other words, it is an inevitable part of human life discussed in different aspects of society including families. The meaning of dominance in society is not clear. Theoreticians have different ideas about conceptualizing aspects of dominance in families however many scholars use the term "decision making" for dominance in families.

Corresponding Author: Ali Edalati, Department of Human Development and Family Studies, Faculty of Human Ecology, University Putra Malaysia, Malaysia Tel: 0060122793206 
When it is questioned who holds authority, it specifically refers to decision making in families. Moreover, the criterion of authority among couples can determine the degree of patriarchy in families (Sarookhani, 2005). Hamby (1996) defines dominance as any attempts that a life partner makes to take control over the other partner. He mentioned three different forms of dominance, i.e., authority, restrictiveness and disparagement. All of these forms are with violence.

Bettencourt and Miller (1996) in their study found that when provocation is present, there is a reduction in the gender differences to aggression. This implies that female aggression is more likely to occur when women feel provoked. Other research found that women are more likely to be provoked through verbal abuse than physical instigations (White and Kowalski, 1994). Based on Coleman and Straus (1986), there are three relationships after marriage: (1) equality (2) men's dominance (3) women's dominance. In their study they found that the equality relationship had the least amount of fights, but men's dominance and women's dominance relationship had the highest risk for violence. They chose 1975 families and identified four groups for making decisions about relationships as follows: Male dominance, female dominance, divided power and equalitarian. They found that most of the families were grouped among divided power and equalitarian parts. They found that when fighting between couples is frequent and it is a women dominant relationship, women's violent behavior toward her husband increases. Another classification is made by Hamby (1996): (1) authority, (2) restrictiveness and (3) disparagement. He defines dominance as any attempts that a life partner makes to take control over the other partner. Feminist theory says that men's dominance over women is basic structure that has lead to victimization of women (Mignon et al., 2002). Dutton (1994) talked about mutually violent couples. Adi (2007) argued that effort to equalize power is one of the motivations for female aggression. The aim of her study was to recognize how women aggression impacts couples in situationally violent relationships and to realize the motivation for the women to use aggression against their husband. She found that the reasons for women aggression against their partner were due to: a desire to equalize the dominance in the relationship, to release built up tension, abandonment, wanting control and retribution but Hamberger and Guse (2002) argued that self defense is as the main reason for women aggression towards her husband while men primarily use aggression in order to dominate and control.

In a measurement research, the data of which have been collected from a sample of 300 married women of
Shiraz, Mansourian and Ghaderi (2003) was investigated in regard to power dominance in families. They studied the effects of socio-economic variables of family power structure. Survey method was used to measure the effects of the variables. In their study, dominance was been measured under two concepts of work distribution pattern and resolution pattern. Based on the results, husband and wife's education is one of the significant variables in relation to power dominance in families. The women who have higher educational levels have a more crucial role in cooperation and resolution. There existed a negative significant relationship between man's education and his exerting power in families. In other words, the more educated the men are, the less power dominance there will be and women have more chances for cooperating in relations.

Mahdavi and Saburi (2003) investigated dominance distribution in families living in Tehran. They studied a 200 married woman sample that had at least one child. According to the outcomes, the structure of $37.5 \%$ of Tehran families is democratic; $39 \%$ of them are democratic only to some extent and $23.5 \%$ of families have structures other than democratic. Factors such as conception of husband's tendency toward exercising power against his wife, women's conception about their obedient roles, women's collaboration in choosing their husbands and women's level of education have had crucial roles in the quality and quantity of democratic structure of families.

Mahdavi and Sabouri Khosrowshahi (2003), in an empirical study on power in the family, studied the structure of power within family in three aspects: symmetric relation, area of power and couple strategy. They attempted to offer a definition of the democratic family, which leads to the construction of scales in order to measure the dimensions of family structure. Social survey was applied as the methodological orientation with a sample covering 200 cases. The findings indicate that the structure of power in the south of Tehran is less democratic than that of north Tehran. Results show that factors such as women's education, their employment and participation in spouse choosing would incline power structure closer to a more democratic family, while submissive self-conception, on the part of women and the authoritarian one, on the part of men, causes power structure to lean toward a less democratic family.

Lajvardi (1997) in her research in Tehran city found that all respondents mentioned that the structure of their family wasn't patriarchal and in most of families they decided mutually $(60 \%)$. Sarookhani and Panahi (2006) studied the effect of power in family on social participation among the adults. They found that 


\section{J. Social Sci., 6 (2): 162-166, 2010}

in those whose family was democratic and egalitarian, their social participation was high. People from these families will participate in adulthood in the destiny of society as a whole; they are true citizens of their society. The study was carried out in Tehran in 2004 and 391 people living in Tehran were included in their study.

Relationship between marital satisfaction and female aggression: Kaplan and Maddux (2002) states that marital satisfaction is an individual experience in marriage which can only be evaluated by each person in response to the degree of marital pleasure. They believe that, it depends upon the individual's expectations, needs and desires in their marriage. Marital satisfaction refers to the degree of satisfaction between a couple. This would mean the degree of satisfaction they feel with their relationship. This satisfaction could be addressed both from the perspective of wife toward the husband or the husband toward the wife.

Marital satisfaction means good feeling of marriage. There is a relationship between marital satisfaction and violence. Researchers such as Lewis and Fremouw (2001) have said that violence and marital satisfaction are bidirectional, that is that there may be low satisfaction in the past that leads to violence or vice-versa.

A number of researchers like Bookwala et al. (1994) have found that in violent couple relationships, lower level of relationship satisfaction exist compared to non violent couple relationships.

Sagrestano et al. (1999) argues that marital satisfaction has a negative relation to physical violence. Despite all of this research, it is not proven that men's or women's dissatisfaction of marriage is a reason for a wife's aggression. Arias et al. (1987) believed that low relationship satisfaction is associated with physical violence and a decrease in attraction to the partner. For example, if relationship satisfaction is low; one of couples may end the relationship. Some factors are linked with a higher life satisfaction like the use of discussion, compromise and calm discussion in the family. In a sample, Byrne and Arias (1997) found that $30 \%$ of women use physical violence against their husbands compared to $25 \%$ of men. They found that women's marital satisfaction was negatively correlated with her use of physical aggression. Dissatisfied women were more likely to use physical aggression.

Some researchers have found that in violent relationships, the husband's marital satisfaction is higher than the wife's satisfaction (Sabourin et al., 1993).

Gottman and Levenson (1999) in their study with 79 couples who were monitored in discussion with one another and were then again monitored in conversation four years later, understood that over time, the couples who were more faithful and not susceptible to change showed more positive affect in their communications with each other. Husbands presented themselves as more fixed over time in terms of treat with contempt and for women defensiveness remained fixed. Moreover, women had more positive and negative affect during conflict than men. They got more involved in positive communication and therefore seemed to consider it to be more important to maintain marital satisfaction in the relationship.

Shachar (1991) studied marital satisfaction with a sample of 206 couples who were married up to four years for the first time. The result revealed a degree of liberalism and the husband's desire to marry were variables that had a significant effect on marital satisfaction.

Shayesteh et al. (2006) mentioned that marital satisfaction and cognitive variables are correlated. Correlation coefficient between marital satisfaction and the belief disagreement is destructive was 0.42 ; mind reading is expected 0.23 , partner cannot change 0.59 , sexual perfectionism 0.32 and innate gender differences account for marital problems 0.12. Correlation between marital satisfaction and non-logical expectations was 0.25 . Furthermore, hierarchical regression analysis revealed that cognitive variables are predicting in total 0.44 of marital satisfaction's variance, from which 0.41 of variances is defined by two communication beliefs: Disagreement is destructive (0.19) and "partner cannot change" (0.22). Their sample was composed of 50 Iranian couples (residents of Canada and Australia). Couples were recruited if accessible or volunteered to participate in this research.

Danesh and Heydarian (2006) investigated the relationship between mutual interest and respect among couples and their marital satisfaction. Result showed that couples and also men and women, who were more respectful and loved their spouse were more satisfied in their married life. There was a positive correlation between the amount of respect and love among couples. The couples who were respectful to their spouses were more satisfied of their married life. Couples who loved their spouses more were satisfied of their married life. The sample was 30 couples that were chosen by random cluster method. The couples filled in a controlled condition three questionnaires: Marital satisfaction, respect to spouse and love and simultaneously and interest scale. Research methods were correlation and expose facto. The Data were analyzed statistically, with "two variable and multivariable regression methods and F- 


\section{J. Social Sci., 6 (2): 162-166, 2010}

test. Finding in $(99 \%)$ confidence or more were showed.

Mirahmadizadeh et al. (2003) argued that marital satisfaction was greater amongst those who were older and had higher level of education at the time of marriage. It was greater among couples who have mutual respect for each other and hold both communication skills and more understanding. Attractiveness alone is less effective on marital satisfaction than investment, positive attitude and understanding. Around 127 volunteers filling for divorce and 1670 married individuals from normal population with no prior history of divorce were studied by Marital Satisfaction Questionnaire which comprises four scales, attractiveness, understanding, attitude and investment. In a multivariate analysis, the most significant relationship factors related to marital satisfaction included investment, attitude and treatment with each other and understanding each other.

Hamidi (2007) found that there is a positive significant relationship between attachment styles and marital satisfaction. Students with secure attachment style indicated higher marital satisfaction than students with insecure attachment styles. No significant difference was found between male and female students in marital satisfaction. There was no significant difference between male and female students in attachment styles.

Rajaei et al. (2007) examined the relationship between the attachment styles and marital satisfaction. Data showed a significant and positive correlation between marital satisfaction and secure attachment, but negative correlations with avoidant and ambivalent attachment styles. Adult attachment styles explained 52\% and attachment to mother styles accounted for $29 \%$ of the variance in marital satisfaction. Males and females were not significantly different in terms of level of marital satisfaction. The individuals sample was 105 married students (54 females and 51 males) who were selected through simple random sampling method.

In another study, Eidi and Khanjani (2006) investigated the influence of attachment style on the rate of marital satisfaction between couples. The results showed significant differences among attachment style with respect to marital satisfaction. The secure people had a higher satisfaction than the other style when both couples had a secure style. The rate of satisfaction is higher than the couples with unsecured attachment. Also it has been indicated that when the style of male and female attachment is even (both secure or both avoidant or both ambivalent) their marital satisfaction is higher than those with an uneven style of attachment. Among attachment styles, the lowest satisfaction belongs to the couples with one with avoidant attachment and another with ambivalent attachment. The other result is that the males had higher marital satisfaction than females.

\section{CONCLUSION}

The review of several studies has shown that female aggression has relationship with dominance and marital satisfaction and it exists in all countries. Unfortunately till the present day, little attention has been given to fully understand dominance, marital satisfaction and relationship with female aggression. A good understanding of the problem occurring inside family can only be achieved if there are more research done to study women dominance and marital satisfaction and the problem around the female aggression. In conclusion, without ample studies on women and their aggression, our picture of family and the problems related to it will not be clear.

\section{REFERENCES}

Adi, S.G., 2007. Understanding Female Aggression in Situationally Violent Relationships: A Qualitative Study. Virginia Polytechnic Institute and State University, Virginia.

Arias, I., M. Samios and K.D. O'leary, 1987. Prevalence correlates of physical aggression during courtship. J. Interperson. Violenc., 2: 82-90.

Archer, J., 2000. Sex differences in aggression between heterosexual partners: A meta-analysis review. Psychol. Bull., 126: 651-680.

Bettencourt, B.A. and N. Miller, 1996. Gender differences in aggression as a function of provocation: A meta-analysis. Psychol. Bull., 119: 422-447.

Bookwala, J., I.H. Frieze and N.K. Grote, 1994. Love, aggression and satisfaction in dating relationships. J. Soc. Person. Relat., 11: 625-632.

Byrne, C.A. and I. Arias, 1997. Marital satisfaction and marital violence: Moderating effects of attributional processes. J. Fam. Psychol., 11: 188-195.

Coleman, D.H. and M.A. Straus, 1986. Marital power, conflict and violence in nationally representative sample of American couples. Violen. Victim., 1: 141-157.

Danesh, E. and M.M. Heydarian, 2006. The relationship between mutual interest and respect among couples and their marital satisfaction in Qom city. J. Counsel. Res. Dev., 5: 59-76. 
Dutton, 1994. Patriarchy and wife assault: The ecological fallacy. Violen. Vict., 9: 167-182.

Eidi, R. and Z. Khanjani, 2006. Investigation the influence of attachment styles on rate of marital satisfaction between couple. J. Psychol. Stud., 1: 175-201.

Gottman, J.M. and R.W. Levenson, 1999. What predicts change in marital interaction over time? A study of alternative methods. Fam. Process, 38: 143-158.

Hamberger, L.K. and C.E. Guse, 2002. Men's and women's use of intimate partner violence in clinical samples. Violen. Against Women, 8: 1301-1331.

Hamby, S.L., 1996. The dominance Scale. Preliminary psychometric properties. Violen. Vict., 11: 199-212.

Hamidi, F., 2007. A study on the relationship between attachment styles and marital satisfaction in married students of teacher training university. J. Fam. Res., 3: 443-453.

Hotaling, G.T. and D.B. Sugarman, 1990. A risk marker analysis of assaulted wives. Fam. Violen., 5: 1-13.

Kaplan, M. and J.E. Maddux, 2002. Goals and marital satisfaction: Perceived support for personal goals and collective efficacy for collective goals. J. Soc. Clin. Psychol., 21: 157-164.

Lajvardi, H., 1997. Power in the Family. Tehran University, Tehran.

Lewis, S.F. and W. Fremouw, 2001. Dating violence: A critical review of the literature. Clin. Psychol. Rev., 21: 105-127.

Mahdavi, M.S. and H. Saburi, 2003. Investigating the structure of power distribution in family. Women Stud., 2: 29-65.

Mahdavi, M.S. and H. Sabouri Khosrowshahi, 2003. The structure of power distribution within the family. Women Res., 1: 27-68.

Mansourian, M.K. and F. Ghaderi, 2003. Fectors affecting power dominance in families of Shiraz. Sci. Res. J., 2: 269-294.
Mignon, S.I., C.J. Larson and W.M. Holmes, 2002. Family Abuse: Consequences, Theories and Responses. Allyn and Bacon, Boston, pp: 140-180.

Mirahmadizadeh, A., N. Nakhai Amroodi, S.H. Tabatabai and R. Shafieian, 2003. Marital satisfaction and related determining effectual factors in Shiraz. J. Psychiatry Clin. Psychol., 8: 56-63.

Sabourin, T.C., D.A. Infante and J.E. Rudd, 1993. Verbal aggression in marriages: Acomparison of violent, distressed but nonviolent and nondistressed couples. Hum. Commun. Res., 20: 245-267.

Sagrestano, L.M., C.L. Heavey and A. Christenson, 1999. Perceived power and physical violence in marital conflict. J. Soc. Iss., 55: 65-79.

Sarookhani, B., 2005. Women, dominance and family. J. Female Res., 3: 29-50.

Sarookhani, B. and A. Panahi, 2006. Power structure in family and social participation. J. Women's Res. (Pazhuhish-I Zanan), 4: 31-60.

Shachar, R., 1991. His and her marital satisfaction: The double standard. Sex Roles, 25: 451-467.

Shayesteh, G., A. Sahebi and A. Alipour, 2006. The study of relationship between couple's relational beliefs and irrational expectations with marital satisfaction. J. Fam. Res., 2: 223-238.

Straus, M.A., 2008. Dominance and symmetry in partner violence by male and female university students in 32 nations. Children Youth Servic. Rev., 30: 252-275.

Rajaei, A.R., M. Nayeri and S. Sedaghati, 2007. Attachment styles and marital satisfaction. J. Iran. Pschol., 3: 347-356.

White, J.W. and R.M. Kowalski, 1994. Deconstructing the myth of the nonaggressive woman: A feminist analysis. Psychol. Women Q., 18: 487-508. 